\title{
Anodic protection obtained by applying Smart Paint in Carbon Steel
}

\author{
R. S. SILVA ${ }^{1}$, V. MAGGI ${ }^{2}$, J. Z. FERREIRA ${ }^{3}$ e A. MENEGUZZI ${ }^{3}$. \\ ${ }^{1}$ Federal University of Rio Grande do Sul, Postgraduate Program in Mines, Metallurgical and \\ Materials \\ ${ }^{2}$ Federal University of Rio Grande do Sul, Department of Materials \\ ${ }^{3}$ Federal University of Rio Grande do Sul, Postgraduate Program in Mines, Metallurgical and \\ Materials, Department of Materials \\ E-mail for contact: sanchotenesilva@yahoo.com.br
}

\begin{abstract}
This work search introduce of a new alternative of organic coating without the presence of hazardous metals and replacement of commercial rectifiers used for protection of oxidized metals by the method of anodic protection. From this, was produced of a Smart Paint (SP), basically composed of a Paint Polyurethane Commercial (PPC) mixed with a $1 \%$ of binder de base PAni EB and plasticizer chemically inert 4chloro-3-methylphenol. After, the SP and PPC were applied in plates of carbon steel, with the use of dip coat technique. SP was characterized by thermal analyzes and physicochemical beyond perform electrochemical tests of Cyclic Voltammetry (CV) and Open Circuit Potential (OCP), in aqueous solution 2 mol. $\mathrm{L}^{-1} \mathrm{H}_{2} \mathrm{SO}_{4}$. The results obtained allow us to state that the application of the binder to the PPC not significantly alters their physicochemical properties, and that the binder adds the ability to induce the formation or maintenance of protective oxides in oxidized metals exposed to harsh environments.
\end{abstract}

\section{INTRODUCTION}

The corrosion is a process spontaneous that occurs from chemical and/or electrochemical reactions of metal substrates or metallic compounds exposed to electrolytic environments, which results in a change of the metallic structure for a chemical conformation of smaller reactivity. The metallic materials may further be subjected to mechanical stress, which can result in acceleration of the corrosion process. (Panossian, 1993, Reberge, 2008).

Currently the corrosion became one of the main factors that hinder the production and maintenance of metallic materials exposed to weather and aggressive media, the corrosive process is the principal is responsible for the degradation and reduced useful life of structures and equipment constituted of metallic substrates. With this, the combat as corrosion has become in a wide field of research in order to promote alternatives that minimize the corrosive action. And, the use of organic coatings (mainly paints and resins) presents with a promising option to inhibit corrosion and prolong the use of metallic materials. (Wicks Jr. et al., 2007).

The organic coatings applied to combat corrosion basically have two methods of protection, which may occur simultaneously or not. The first method is represented by the formation of an 


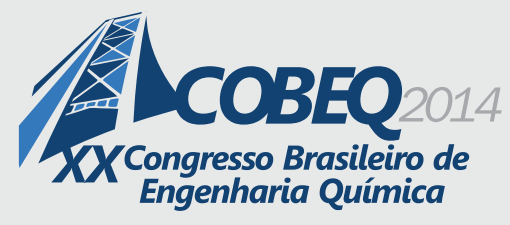

19 a 22 de outubro de 2014

Florianópolis/SC

impermeable physical barrier preventing infiltration of aqueous solutions containing or not, aggressive ions $\left(\mathrm{H}_{2} \mathrm{SO}_{4}, \mathrm{HClO}_{4}\right.$, etc.), with or without the presence of oxygen, until the metal of interest. The second method occur by the production a coating constituted of elements (pigments or resins) that a provide specific protection (cathodic or anodic protection) to the substrate metallic. This protection method has the disadvantage of have been consolidated from the incorporation of dangerous metals $(\mathrm{Cd}, \mathrm{Pb}, \mathrm{Cr}, \mathrm{Ni}$ and others) for formation of anticorrosive organic coatings, which represented a new demand of research that search to develop or aggregate new elements that would constitute the organic coatings form active against corrosion and at the same time, providing the lowest possible environmental impact (Amo et al., 2002; Wicks Jr. et al., 2007).

Conform Akbarinezhad et al. (2009) and Alemán et al. (2008), polyaniline (PAni), an intrinsically conductive polymers (ICP) have been presented in recent years as a promising component to be researched to constitute anticorrosive organic coatings, due to their properties such as the low cost of the monomer (aniline), solubility determined in organic solvents, ease of synthesis, good stability under certain environmental conditions and both in the form not conductive as conductor has the ability to produce oxidation-reduction reactions in the region of potential compatible with the formation and / or preservation of passivating oxides for various metals.

The use of PAni in oxidized state and driver, known as protonated emeraldine polyaniline (PAni EP), has been widely used in research for the formation of protectors coatings in the form of pigment dispersed in polymeric matrix (resin or commercial paint), method that does not allow the physical connection between the ICP its polymer chains, the electrolyte and the metal. (Baldissera et al., 2012). Conform Silva et al. (2012), is promising the use of PAni on state oxidized and nonconductive, known as emeraldine base polyaniline (PAni EB) because this ICP presents a low electronic conductivity and or ionic in relation to PAni EP, which represents a low diffusion of ions, and assists the barrier effect produced by the coating constituted of PAni EB. Furthermore, the PAni EB has the ability to form free-standing resins, ie, films with sufficient cohesion and homogeneity to the application in a metallic surface.

This work aims the production of a Smart Paint (SP) that can maximize the electrochemical capacity of PAni EB and allow the optimization of the formation and maintenance of passivation of AISI 1010 steel exposed to an aggressive environment, represented in Figure 1. With this, seeks to introduce a new option that can replace organic coating anticorrosive coatings or methods of higher environmental impact. This coating was produced by the mixing a Polyurethane Paint Commercial (PPC) and a binder constituted by the PAni EB, the electrochemically inert plasticizer, 4-chloro-3methylphenol (CMP), and to control the viscosity and dispersion of PAni and CMP, was used the solvent dichloromethane $\left(\mathrm{CH}_{2} \mathrm{Cl}_{2}\right)$.

The SP was characterized by thermal assays of Thermogravimetric Analysis (TGA), aiming to identify whether or not the interaction of PAni EB with plasticizer and PPC. After application of SP on plates of AISI 1010 steel, were performed electrochemical tests Cyclic Voltammetry (CV) and Open Circuit Potential (OCP), where if sought to analyze the performance of the SP and its ability to promote anodic protection in an environment aggressive, as the aqueous 2 mol.L $\mathrm{L}^{-1}$ of $\mathrm{H}_{2} \mathrm{SO}_{4}$. 


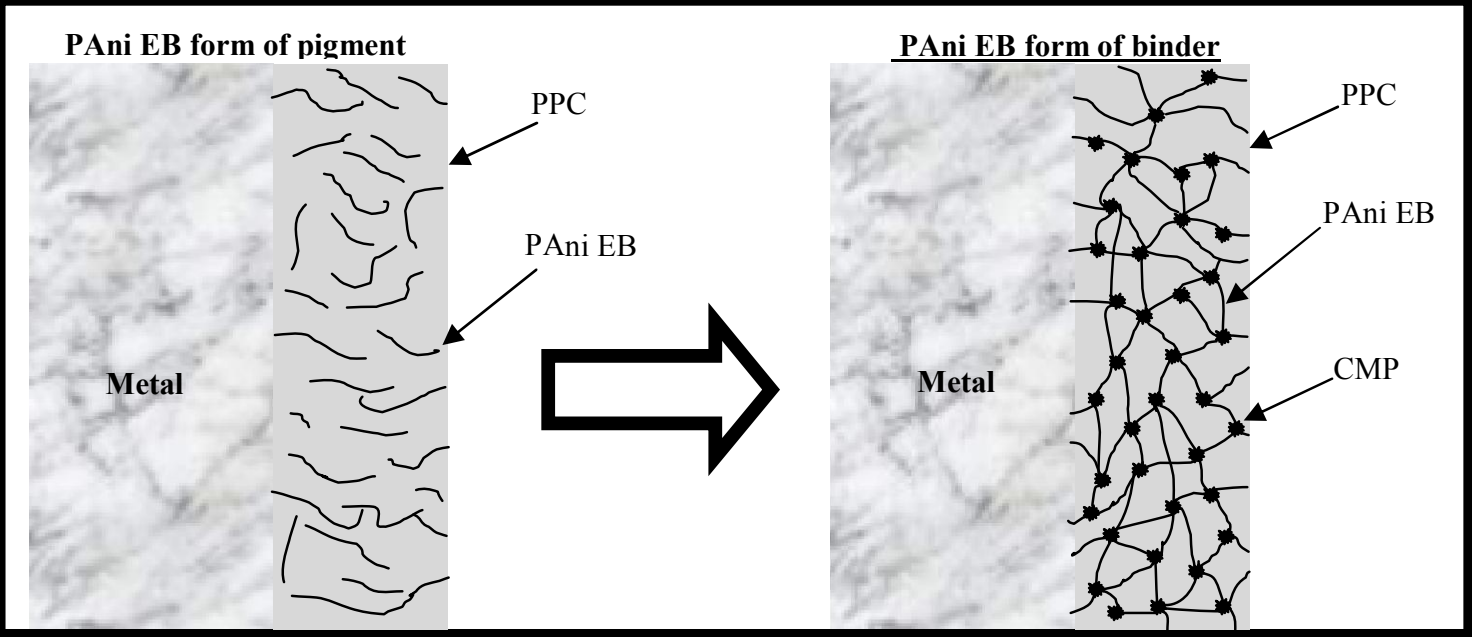

Figure 1 - Schematic representation of underutilization and maximum utilization of the electrochemical capacity of the ICP associated with a commercial organic coating, such as PPC.

\section{MATERIALS AND METHODS}

\subsection{Production of binder PAni EB and SP}

The formulation of the binder PAni EB occurred from the mixture of PAni EB, the CMP and the organic solvent $\mathrm{CH}_{2} \mathrm{Cl}_{2}$, the proportion in weight of $1: 2: 10$, respectively. These components were submitted to intense agitation with the aid of high speed disperser Dispermat Model N1, in bottle closed for a period of $2 \mathrm{~h}$, with the aim of dispersing and homogenizing the mixture of PAni EB and CMP contained in the binder (Silva et al., 2012).

After obtaining of the binder with the desired characteristics, was carried the production of SP, from the mixture of the binder de PAni EB in the concentration of $1 \%(w / w)$ on a PPC, with the aid of a balls mill Dispermat SL, containing zirconium balls in rotation speed of $1000 \mathrm{rpm}$ for $30 \mathrm{~min}$ period, showed in the Figure 2.

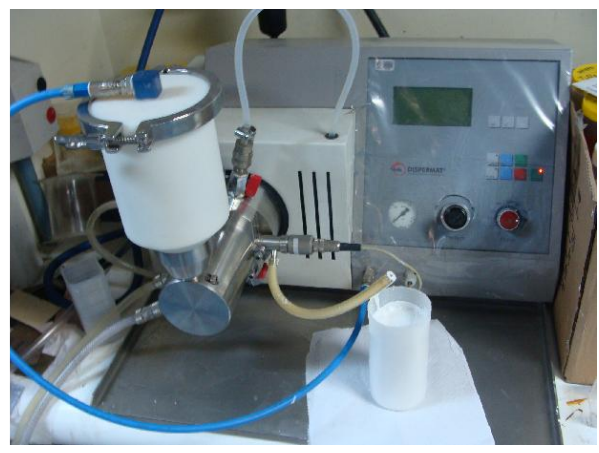

Figure 2- Image of production of SP. 


\section{9 a 22 de outubro de 2014 \\ Florianópolis/SC}

\subsection{Preparation Metallic Substrates}

For the application of SP and PPC was required prior preparation of plates AISI 1010 steel used in the study. The metallic substrates with dimensions of $50 \mathrm{~mm} \times 100 \mathrm{~mm} \times 1 \mathrm{~mm}$, for being cold laminates, were subjected to only the alkali degreasing process.

With this, the steel plates were immersed in 619L Saloclean solution in the concentration of $5 \%(\mathrm{w} / \mathrm{v})$, at a temperature of $45^{\circ} \mathrm{C}$ for a period of $15 \mathrm{~min}$. After, was carried washing the parts with jets of deionized water and drying with jets air to the approximate temperature of $60{ }^{\circ} \mathrm{C}$, thus were obtained plates free of impurities for the application of the coatings already indicated.

\subsection{Application of PPC and SP}

The PPC (without binder PAni EB) and the SP produced were applied on plates AISI 1010 steel, where was used the method of application dip coat, with the use of equipment Deep Coating Elevador de Disco MA 765-Marconi, the sink rate used was $300 \mathrm{~mm} / \mathrm{s}$, the immersion time of $10 \mathrm{~s}$ and the output speed is $300 \mathrm{~mm} / \mathrm{s}$. Posteriorly, the samples were dried at room temperature during 48 h.

\subsection{Thermal Analyzes}

The samples used for thermals analyzes were obtained from the application of the binder PAni EB, PPC and SP on plates plan and no adherent glass, allowing evaporation of the solvent and the formation of free-standing films. TGA was performed using the equipment Thermogravimetric Analyzer Model Q50 from TA Instruments, the temperature range used was 25 at $900{ }^{\circ} \mathrm{C}$ under $\mathrm{N}_{2}$. The heating rate used for all samples was $20^{\circ} \mathrm{C} / \mathrm{min}$.

\subsection{Electrochemical Assays}

The tests electrochemical of $\mathrm{CV}$ and $\mathrm{OCP}$ were conducted using a three-electrode electrochemical cell, containing as working electrode the AISI 1010 steel with or without coating, reference electrode used was the $\mathrm{Ag} / \mathrm{AgCl}$ and counter electrode the $\mathrm{Pt}$ wire $99.99 \%$. The tests were developed in the aggressive environment of $\mathrm{H}_{2} \mathrm{SO}_{4}$ in concentration of 2 mol. $\mathrm{L}^{-1}$, with the aid of the equipment Potentiostat/Galvanostat AUTOLAB PGSTAT 302 Ecochemie and of the software GPES.

\section{Results and Discussions}

\subsection{Thermal Analyzes}

The TGA analyzes utilized $10.204 \mathrm{mg}$ of film of the binder PAni EB, $10.769 \mathrm{mg}$ of PPC and $10.719 \mathrm{mg}$ of SP, supposedly formed from the evaporation of the solvent. As Figure 3 and Table 1, it was possible to verify that in the temperature range from 25 to $200{ }^{\circ} \mathrm{C}$, the weight loss of the binder of PAni EB film can be attributed to the boiling process of CMP, while samples PPC and SP presented a low weight loss, which can be associated with the presence of moisture and other volatile elements 
contained in the samples. The temperature interval 201 to $500^{\circ} \mathrm{C}$ the binder PAni EB presented a weight loss of $19.19 \%$, result that corresponds the total loss of plasticizer and structural degradation of the polymeric chains of the ICP, the PPC and SP presented weight losses of approximately $42 \%$, respectively, the which can be associated with structural changes of the polymer forming of the resin with degradation of urethane groups and/or structural degradation associated with the ICP, because the variations of weight loss SP are according with the results obtained by the film PAni. (Alves et al., 2010; Chattopadhyay et al., 2009).

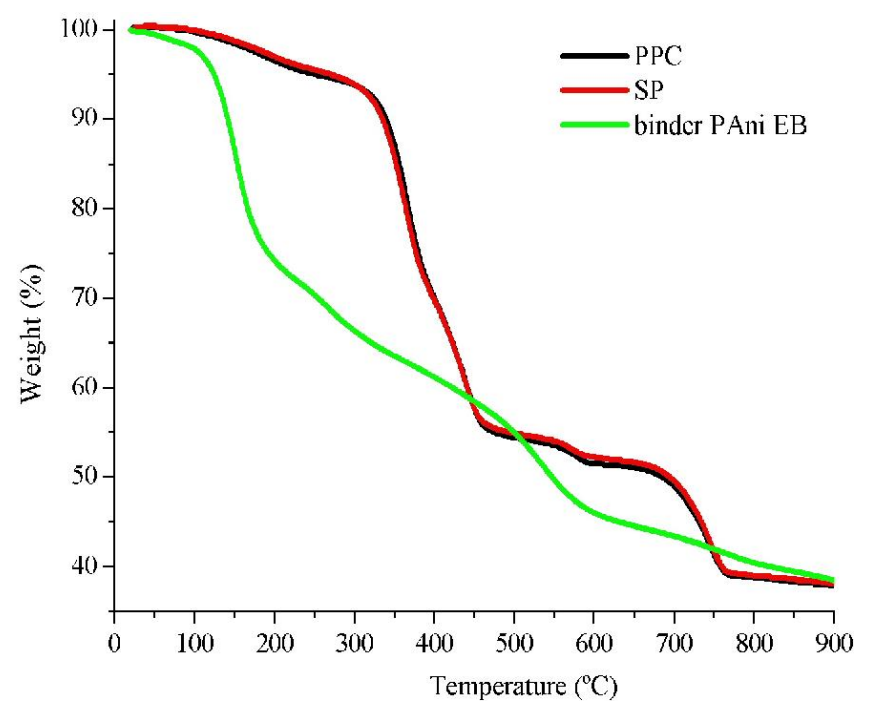

Figure 3 - TGA of PPC, SP and film of binder PAni EB.

Table 1: Weight loss (\%) in the range of temperature of 25 to $900{ }^{\circ} \mathrm{C}$

\begin{tabular}{|c|c|c|c|}
\hline T ( $\mathbf{(} \mathbf{C})$ & PPC (\%) & SP (\%) & binder PAni EB (\%) \\
\hline $\mathbf{2 5}$ a 200 & 3.43 & 2.98 & 25.85 \\
\hline $\mathbf{2 0 1}$ a 350 & 9.28 & 11.28 & 10.63 \\
\hline $\mathbf{3 5 1}$ a 500 & 32.87 & 30.88 & 8.56 \\
\hline $\mathbf{5 0 1}$ a 750 & 13,00 & 13,06 & 13.01 \\
\hline $\mathbf{7 5 0}$ a 900 & 3.53 & 3.64 & 3.48 \\
\hline
\end{tabular}

The temperature interval 501 to $900{ }^{\circ} \mathrm{C}$, the binder PAni EB showed a weight loss that corresponds to degradation of structural fragments of the ICP. The temperature range 501 to $750{ }^{\circ} \mathrm{C}$, PPC and SP showed weight losses which may correspond components degradation of urethanics groups (polyols and isocyanates), already in the temperature range 751 to $900{ }^{\circ} \mathrm{C}$, should occur the deterioration of the structural fragments of these groups, in case of SP should be associated fragments of PAni EB (Alves et al., 2010; Chattopadhyay et al., 2009).

From the thermograms obtained by TGA, it was possible to identify the low physicochemical or nonexistent interaction of binder PAni EB to PPC in order to form the SP, because despite of the 
concentration low (1\%), the results presented were consistent, mainly in the temperature range 201 to $500{ }^{\circ} \mathrm{C}$, in which the components (PAni EB and CMP) of binder, that form the SP, are practically removed or degraded, represented on the increase and decrease of weight losses of SP according to the weight loss of binder PAni EB film. This result allows indicate that the SP is formed by the evaporation of the solvent, and after this process, the PAni EB and forming polymer resin retains its thermal properties.

\subsection{Electrochemical tests}

The electrochemical characterization assay of CV was carried in sample of uncoated AISI 1010 steel, with the aim of identifying potential values start and end of passivation zone of the metal to be exposed to the aqueous medium of $\mathrm{H}_{2} \mathrm{SO}_{4}$ in concentration of 2 mol.L ${ }^{-1}$, as shown in Figure 4(a). This test occurred from the potential scan of -1.00 to $+2.00 \mathrm{~V}_{\mathrm{Ag} / \mathrm{AgCl}}$, where it was observed that the potential of -1.00 to $-0.50 \mathrm{~V}_{\mathrm{Ag} / \mathrm{AgCl}}$ presents a cathode active region (reduction) in that metal it is immune to electrolytic medium. Posteriorly, the potential reaches an anodic active region (oxidation) that represents the metal corrosion. The potential interval between +0.39 to $+1.75 \mathrm{~V} / \mathrm{Ag} / \mathrm{AgCl}$, has initial the passivation region with the indication of the Flade potential of the metal $(+0.39 \mathrm{~V} \mathrm{Ag} / \mathrm{AgCl})$, occurs where stabilization of the current density $\left(\mathrm{I}\left(\mathrm{A} \cdot \mathrm{cm}^{2}\right)\right)$, that indicates the formation of a compact and adherent layer of iron oxides. After the potential $+1.75 \mathrm{~V}_{\mathrm{Ag} / \mathrm{AgCl}}$, occurs the pseudo-transpassivation process that allows the evolution of oxygen in gas form (Panossian, 1993).
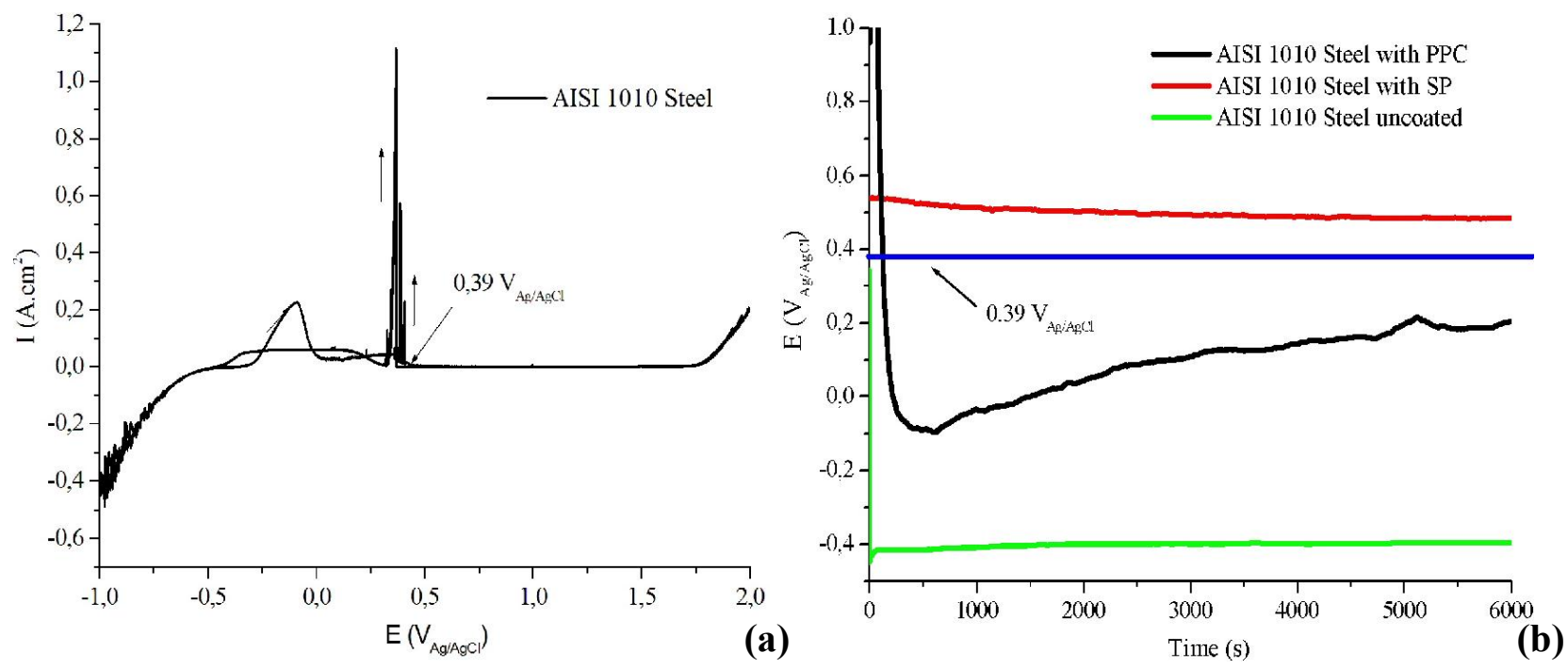

Figure 4 - (a) CV of AISI 1010 steel without coating; (b) OCP of AISI 1010 steel uncoated, coated PPC and coated SP.

Electrochemical assays of OCP were carried during time given of $6000 \mathrm{~s}$ with an initial polarization $+1.00 \mathrm{~V}_{\mathrm{Ag} / \mathrm{AgCl}}$ during $5 \mathrm{~s}$, in order to inhibit oxidation (surface) of the metal to be exposed to the environment. As Figure 4(b), the AISI 1010 steel undercoated showed constant potential along of the analysis of $-0.41 \mathrm{~V}_{\mathrm{Ag} / \mathrm{AgCl}}$, this result indicates the presence of the corrosion process in the metal. The sample of coated steel PPC presented a initial decay in the potential -0.10 to 


\section{9 a 22 de outubro de 2014 \\ Florianópolis/SC}

$\mathrm{V}_{\mathrm{Ag} / \mathrm{AgCl}}$, until the time of $611 \mathrm{~s}$, after the potential rises until $+0.20 \mathrm{~V}_{\mathrm{Ag} / \mathrm{AgCl}}$, in the time of $600 \mathrm{~s}$. The result obtained for the carbon steel coated with PPC indicates the elevation of the potential a region of potential more noble than the uncoated sample, but still in the band of potential the indicates metal dissolution, i.e., metal corrosion. The AISI 1010 steel coated with SP showed as initial potential +0.54 $\mathrm{V}_{\mathrm{Ag} / \mathrm{AgCl}}$ during the analysis the potential if stabilized at $+0.48 \mathrm{~V}_{\mathrm{Ag} / \mathrm{AgCl}}$ and remaining until the end of the assay. This potential if characterized within of the region passivation of the metallic substrate for this determined aggressive environment, as shown in Figure 4.

The results presented in trials of OCP allow suggest that the presence of binder PAni EB in the composition of SP provides training and/or maintenance of a protective surface layer of protectors oxides on the surface of the metallic substrate to be protected, making it more resistant there action of the medium, for a minimum of $6000 \mathrm{~s}$. This process of corrosion inhibition is known with anodic protection, should also be associate to possible barrier effect produced by the applied coating on the metal.

\section{CONCLUSION}

According to the TGA analyzes, PPC and CMF present if nonexistent, a minimal physicochemical interaction with the PAni EB, the which represent the maintenance of their electrochemical properties. The electrochemical assays showed that the SP has the ability to raise the potential of the metal/paint/electrolyte system for parameters that can impede the action of the corrosive process. This is due to the performance of the ICP which induces the formation and/or maintenance of protectors oxides that inhibit corrosion of AISI 1010 steel, for a minimum time of $6000 \mathrm{~s}$.

With this, the use of binder PAni EB in the formation of SP, if presented as a new option of organic coating that can act effectively at inhibiting corrosion, through the method of anodic protection for a specified period. Besides promoting the replacement of toxics traditional components in anticorrosive paints commercially available until today.

\section{ACKNOWLEDGMENT}

The authors thank CNPq and CAPES.

\section{REFERENCES}

AKBARINEZHAD, E.; EBRAHIMI, M; FARIDI, H. R. Corrosion inhibition of steel in sodium chloride solution by undoped polyaniline epoxy blend coating. Prog. in Org. Coat., v. 64, n. 4, p. 361364, 2009.

ALEMÁN, C.; FERREIRA, C. A.; TORRAS, J.; MENEGUZZI, A.; CANALES, M.; RODRIGUES, M. A. S.; CASANOVAS, J. On the molecular properties of polyaniline: a comprehensive theoretical study. Pol., v. 49, n. 23, p. 5169-5176, 2008. 
ALVES, W.; VENANCIO, E. C.; LEITE, F. L.; KANDA, D. H. F.; MALMONGE, L. F.; MALMONGE, J. A.; MATTOSO, L. H. C. Thermo-analyses of polyaniline and its derivatives. Thermochim. Act., v. 502, n. 1-2, p. 43-46, 2010.

AMO, B.; ROMAGNOLI, R.; DEYÁ, C.; GONZÁLEZ, J. A. High performance water-based paints non-toxic anticorrosive pigments. Prog. in Org. Coat., v. 45, n. 4, p. 389-397, 2002.

BALDISSERA, A. F.; FERREIRA, C. A. Coatings based on electronic conducting polymers corrosion protection of metals. Prog. in Org. Coat., v. 75, n. 3, p. 241-247, 2012.

CHATTOPADHYAY, D. K.; WEBSTER, D. C. Thermal stability and flame retardancy of polyurethanes. Prog. in Pol. Scien., v. 34, p. 1068-1133, 2009.

PANOSSIAN, Z. Corrosão e proteção contra corrosão em equipamentos e estruturas metálicas. São Paulo: Instituto de Pesquisas Tecnológicas, v. 1, 1993.

ROBERGE, P. R. Corrosion Engineering: principles and practice. New York: McGraw-Hill Companies, 2008.

SILVA, R. S.; CARDOZO, H. M.; FERREIRA, J. Z.; FERREIRA, C. A.; MENEGUZZI, A. Filme Autosuportado de Polianilina Desdopada para Aplicações Anticorrosivas. Pol., v. 22, n. 3, p. 288-294, 2012.

WICKS Jr., Z. W.; JONES, F. N.; PAPPAS, S. P.; WICKS. D. A.; Organic Coatings: science and technology. New Jersey: John Wiley \& Sons, 2007. 